\title{
The Application of Positive Psychology in Ideological and Political Education
}

\author{
Wang Yuanyuan \\ Ideological and Political Department of Xi'an Peihua University, \\ Xi'an, Shaanxi 710125, China \\ e-mail:64789178@qq.com
}

\begin{abstract}
Under the enlightenment of positive psychology, the ideological and political education of college students from the "view" to "advantage perspective", from "single subject" to "multidisciplinary" fusion, from "passive coping" to "positive interaction". To innovate education method, we should pay attention to the theory and practice combined with each other, let students' beliefs and judgments towards a more positive, so as to enhance the actual effect of ideological and political education.
\end{abstract}

Keyword-Positive Psychology; Ideological Politics; College Student

The ideological and political education of college students is facing new problems in the new period. The psychological status, behavior norms and social environment changes of college students exert a subtle influence on the ideological and political education. The education of socialist core values as a guide, the theoretical education of the students, the education of revolutionary tradition, the situation and policy education, help students to establish a correct world outlook, outlook on life and values, the education in the part of the students have not obvious. In practical work, the educational implementer failed to understand the students and care for the students, and did not create more relaxed space, more opportunities and more adequate nutrition for the students' personalized growth. This leads to the bottleneck of Ideological and political education for college students, and the development of positive psychology opens up a new perspective for ideological and political education. Applying positive psychology to improve students' political quality and enable students to face life positively, which can improve the effectiveness of Ideological and political education.

With the change of social environment, college students have deeper thinking and requirements for society and country. With the development of dialectical thinking, critical thinking and creative thinking of college students, the thought is not mature. Healthy mental state is the basis of forming good political and moral quality. The use of positive psychology moral education is to cultivate the ideal, pursuit, effective way to play the young generation. With positive psychological quality and noble moral character, we can make unremitting efforts to realize the great rejuvenation of the Chinese nation.

\section{THE DEVELOPMENT OF POSITIVE PSYCHOLOGY}

Positive psychology was initiated by American psychologist Seligman, and began to rise in the United States at the end of last century. It redefines many psychological phenomena and psychological problems, encourages people to treat things around with a positive attitude, and shifts the focus of psychological research from "psychological problems" to "positive forces of human beings". The development of positive psychology has gradually formed a "positive psychology movement", which affects all fields, including psychology. Even when people are in adversity, positive psychology can also help people use positive forces to survive and develop, enhance their sense of happiness, and promote the development of individuals and society. Positive psychology is used in various fields to help people better adapt to modern life.

At the end of the twentieth Century, scholars from Tsinghua University began to introduce the concept of 
positive psychology, and then the educational and psychological circles began to pay attention to the development and practical application of positive psychology. Lei Li, Ye Haosheng, Ren Jun and other scholars introduced positive psychology China. A large number of monographs and periodicals demonstrate the connection and development of Ideological and political education and positive psychology in Colleges and universities. With the change of times, the ideological and political education of college students also presents more characteristics. When college students are in complex social reality, their immature minds do not know how to conduct moral judgment and how to have effective moral behavior, which makes them not good at making moral choices. When they face the conflicts between the real world and their increasingly mature world outlook, outlook on life and values, positive psychology can help college students correctly understand conflicts and avoid causing anomie. Using positive psychology to guide the ideological and political education of college students can open up the ideas and horizons of Ideological and political educators. In the process of Ideological and political education, positive psychology helps college students set up the idea of pursuing lifelong happiness, which is more conducive to the healthy growth of College students.

At present, the research of Ideological and political education from the perspective of positive psychology is developing towards the understanding of the process of positive change, and researchers begin to think about how to strengthen the effect of Ideological and political education from a broader background. Therefore, ideological and political education, under the influence of positive psychology, opened up a new research direction. It pays attention to the factors that can be changed in the process of Ideological and political education, such as education ideas, education vision, education environment, etc.. In the process of education, we should pay attention to the positive role, not only pay attention to the negative factors in the process of Ideological and political education. Through the study of these problems can help college students to adapt to external challenges and potential problems of sexual behavior correction, and promote the healthy development of College students.

\section{POSITIVE PSYCHOLOGY INJECTS NEW VITALITY INTO} THY IDEOLOGICAL AND POLITICAL EDUCATION OF COLLEGE

\section{STUDENTS}

The integration of Ideological and political education with positive psychology has injected new theoretical perspectives and new ideas into Ideological education. In positive psychology as a new starting point, educators should pay attention to the students' potential and advantage, advance the positive education for students, cultivating the correct world outlook, outlook on life and values, they can avoid problems, prevent trouble before it happens. In the process of College Students' growth, we should cultivate excellent moral quality, take students as the foundation, give humanistic care to students, pay attention to the combination of theory and practice, and effectively improve the quality of Ideological and political education.

\section{A. Cultivate the positive personality characteristics of College Students}

Political education, ideological education, moral education, law education and psychological education is considered to be the five aspects of the ideological and political education. The psychological health education of college students is often conducted by the students when they have psychological problems or obstacles. For the normal students' psychological training, we seldom pay attention to the mental health education, and the shaping of positive personality has also been neglected for a long time.

In positive psychology, positive personality consists of two independent dimensions. The first: positive individualism, in which individuals can accept themselves, have personal goals, feel meaningful about life, and face the challenges of the environment. Second, Positive relationship with others, good interpersonal relationship can help you when you need help, but also willing to help others. In the ideological and political education process, the application of positive psychology, so that students learn optimistic, optimistic, positive people. Encounter setbacks, difficulties encountered, do not give up easily. 
With the rise of positive psychology, researchers began to pay attention to some positive psychological factors in Ideological and political education, such as positive attitude, happiness, communication and good interpersonal relationship. At the same time, some scholars also re-examine the negative factors, to find its positive role in the ideological and political education, for example, when misfortune is unavoidable, positive coping style can not only help students overcome difficulties, but also can promote the growth of students. The study found that coping styles were positively related to positive mental attitude: positive attitude students used more positive coping styles, while lazy avoidance students adopted more passive coping styles. We study the students' stress, coping strategies and the relationship between well-being, stress, coping style were found to have significant predictive effect of pressure has a significant negative effect on the life of happiness, but if students can take positive coping pressure have positive effect on happiness. We through positive and optimistic mentality education in the ideological and political theory courses, teaching process and normal class contrast, simultaneous contrast effect of pressure in the face of a positive attitude and negative attitude of happiness, the research found that some students under pressure, positive and optimistic attitude showed great psychological adaptability, dynamic pressure become students motivated. When faced with the pressure, the ideological education support system plays an important role in coping with the pressure of study, life and employment.

\section{B. Building a positive campus cultural environment}

Campus environment affects the training and development of talents. The embodiment, cultivation and exertion of creativity are influenced by the surrounding environment. How to make the students' beliefs and judgments towards a more positive, is to make the campus full of vitality. Due to the rise of positive psychology, educators are increasingly aware of efforts to create a vital and positive thinking can promote the positive qualities of the students themselves, the system environment, in order to enhance students' motivation and goals, to face their own development.
To create a good campus culture, campus culture is the school teachers and students in the long-term teaching and research activities, social services, entertainment and other activities in the co creation and formation, is an important manifestation of the future competitiveness and social influence. Campus culture exerts a subtle influence on students' value orientation, mode of thinking and rules of conduct. In the classroom teaching, the construction of inter subjectivity teaching mode, can use multiple interactive teaching, combined with the reality of students, to the center of learning, exchange of teachers and students to carry out the theme of equality, discussions, debates, lectures, performances and other forms of teaching, let the students to show themselves, build self-confidence, cultivate students' positive personality. At the same time, teachers should also face students with positive emotions. Teachers with a sense of happiness can teach students who have a sense of happiness. The teachers will put the idea of positive psychology through the teaching process, and influence and nurture students. In addition, to carry out colorful campus activities, such as lectures, salons, associations, competitions, social practice, and so on, to expand the broader field of students' psychological development.

Campus culture is an important part of Ideological and political education. Optimize the campus environment system and build an environment conducive to students' growth and success. From the management and teaching to attract and infect the students, form a good style of study. Positive psychology, both in theory and in practice, has been shown to release students' internal vitality and potential, and significantly increase their immunity against external difficulties.

\section{PATH CONSTRUCTION OF COLLEGE STUDENTS' \\ IDEOLOGICAI AND POLITICAL EDUCATION FROM THE} PERSPECTIVE OF POSITIVE PSYCHOLOGY

After 90 and 95, college students are positive and optimistic, self-motivated, and have a strong sense of becoming a useful person. They have strong ability to accept, kind, good at communication. In the learning process of daily life, they showed a distinct personality characteristics, 
most of the students living without parents, to create a good learning environment for their life as much as possible, it can be said that they are growing up in the state under the psychological superiority. So, on the whole, they have a very distinct advantage. But at the same time, after years of education, we find that they also have obvious deficiencies. Due to the superior living and learning environment, they cannot adapt to sudden changes. When experiencing some setbacks, psychology is prone to fluctuations, coupled with poor psychological adaptability, so it is easy to produce certain psychological confusion, thereby affecting the normal learning life. In this regard, we should pay attention to the construction of Ideological and political education:

1) Pay attention to cultivating positive emotions of College students. From the aspect of university students concerned about the problem of transfer to pay attention to the cultivation of College Students' positive quality, is also actively prevent turning from saving lives, the advantages of many students motivation, improve students' ability of self-education. Pay attention to EQ education, help students understand the meaning of happiness and how to obtain happiness.

2) Pay attention to the integration of multi subjects. Positive psychology is a new research direction. The ideological and political education of college students can be based on psychological education. The application of scientific methods has an impact on students' cognition, emotion, will and belief. So, focus on the integration of many disciplines, to help students examine the ideological problems from multiple perspectives, positive psychology advantages, rich ways and means of Ideological and political education help us to effectively prevent and solve ideological problems in students.

3) To build a good educational environment, including positive family environment, positive school environment and positive network environment. In the past, we neglected the influence of family environment and the negative influence of virtual network on students. Change from negative response to positive interaction in the future. Actively grasp the right to speak online, give full play to the role of the ideological and political education, so that the positive environment of College Students' beliefs and judgments toward more positive.

The study of Ideological Education in the field of psychological research needs to consider from a broader context how to have a better outlook on life. Pay attention to the factors that can change and play a positive role in mind. Ideological education support system is becoming the focus of positive psychology research. Through the study of these problems can help form positive psychology and ideological and political education external challenges and potential interactive behavior, and promote the effective development of Ideological and political education. It is of great significance to shape the world outlook, outlook on life and values of College students.

\section{ACKNOWLEDGMENT}

This paper is the result of the special research project of Ideological and political education for Xi'an Peihua University students in 2016. Project Name: Strengthening the effectiveness of Ideological and political education of college students from the perspective of positive psychology; project number: PHSZ20161103

\section{REFERENCES}

[1] [America] Christopher Pedersen. Positive psychology [M]. Beijing: Qunyan press, 2010.

[2] Zhang Xiaofeng. On the effectiveness of Ideological and political education of college students from the perspective of positive psychology [J]. School party building and ideological education, 2012, (9)

[3] Zhu Jiguang. A probe into the happiness of College Students' Ideological and political education from the perspective of positive psychology [J]. Ideological and political education, 2009, (5)

[4] Ren Jun. Positive psychology [M]. Shanghai Education Press,2006

[5] Cheng Shuzhen. Introducing positive psychology into college students' Ideological and Political Education[J]. Enterprise research, 2013, (12) 